\title{
Recurrent microdeletion at I7q I 2 as a cause of Mayer-Rokitansky-Kuster-Hauser (MRKH) syndrome: two case reports
}

Laura Bernardini ${ }^{1}$, Stefania Gimelli², Cristina Gervasini ${ }^{3}$, Massimo Carella ${ }^{1}$, Anwar Baban ${ }^{4,5}$, Giada Frontino ${ }^{6}$, Giancarlo Barbano ${ }^{7}$, Maria Teresa Divizia ${ }^{4}$, Luigi Fedele ${ }^{6}$, Antonio Novelli1, Frédérique Béna ${ }^{2}$, Faustina Lalatta ${ }^{8}$, Monica Miozzo ${ }^{3}$ and Bruno Dallapiccola*1

Address: ${ }^{1}$ "Casa Sollievo della Sofferenza" Hospital, IRCCS, S San Giovanni Rotondo, Italy, ${ }^{2}$ Genetic Medicine, University Hospitals of Geneva, Geneva, Switzerland, ${ }^{3}$ Division of Medical Genetics, San Paolo School of Medicine, University of Milan, Milan, Italy, ${ }^{4}$ Molecular Genetics Unit, G Gaslini Children's Hospital, Genoa, Italy, ${ }^{5}$ Cardiology Unit, Molecular Genetics Unit, G Gaslini Children's Hospital, Genoa, Italy, ${ }^{6}$ Department of Obstetrics, Gynaecology and Neonatology, Fondazione Policlinico-Mangiagalli-Regina Elena, University of Milan, Italy, ${ }^{7}$ Department of Nephrology, G Gaslini Children's Hospital, Genoa, Italy and ${ }^{8}$ Clinical Genetic Unit, Department of Obstetrics and Pediatrics, University of Milan, Fondazione Policlinico-Mangiagalli-Regina Elena, University of Milan, Italy

Email: Laura Bernardini - l.bernardini@css-mendel.it; Stefania Gimelli - stefania.gimelli@gmail.com;

Cristina Gervasini - cristina.gervasini@unimi.it; Massimo Carella - m.carella@operapadrepio.it; Anwar Baban - anwarbaban@yahoo.com;

Giada Frontino - giada.frontino@unimi.it; Giancarlo Barbano - giancarlobarbano@ospedale-gaslini.ge.it;

Maria Teresa Divizia - mariateresadivizia@unige.it; Luigi Fedele - luigi.fedele@unimi.it; Antonio Novelli - a.novelli@css-mendel.it;

Frédérique Béna - frederique.bena@hcuge.ch; Faustina Lalatta - f.lalatta@policlinico.mi.it; Monica Miozzo - monica.miozzo@unimi.it;

Bruno Dallapiccola* - dallapiccola@css-mendel.it

* Corresponding author

Published: 4 November 2009

Orphanet Journal of Rare Diseases 2009, 4:25 doi:10.1 I86/1750-1 I72-4-25

This article is available from: http://www.ojrd.com/content/4/I/25

(C) 2009 Bernardini et al; licensee BioMed Central Ltd.

This is an Open Access article distributed under the terms of the Creative Commons Attribution License (http://creativecommons.org/licenses/by/2.0), which permits unrestricted use, distribution, and reproduction in any medium, provided the original work is properly cited.
Received: 22 July 2009

Accepted: 4 November 2009

\begin{abstract}
Background: Mayer-Rokitansky-Kuster-Hauser syndrome (MRKH) consists of congenital aplasia of the uterus and the upper part of vagina due to anomalous development of Müllerian ducts, either isolated or associated with other congenital malformations, including renal, skeletal, hearing and heart defects. This disorder has an incidence of approximately I in 4500 newborn girls and the aetiology is poorly understood.

Methods and Results: we report on two patients affected by MRKH syndrome in which array-CGH analysis disclosed an identical deletion spanning $1.5 \mathrm{Mb}$ of genomic DNA at chromosome 17q/2. One patient was affected by complete absence of uterus and vagina, with bilaterally normal ovaries, while the other displayed agenesis of the upper part of vagina, right unicornuate uterus, non cavitating rudimentary left horn and bilaterally multicystic kidneys. The deletion encompassed two candidate genes, TCF2 and LHXI. Mutational screening of these genes in a selected group of $20 \mathrm{MRKH}$ females without $17 q 12$ deletion was negative.

Conclusion: Deletion $17 q / 2$ is a rare albeit recurrent anomaly mediated by segmental duplications, previously reported in subjects with developmental kidney abnormalities and diabetes. The present two patients expand the clinical spectrum associated with this imbalance and suggest that this region is a candidate locus for a subset of MRKH syndrome individuals, with or without renal defects.
\end{abstract}




\section{Introduction}

Mayer-Rokitansky-Küster-Hauser (MRKH) syndrome (MIM 277000) affects about 1 in 4500 female births, presenting with congenital aplasia of the uterus and the upper part of vagina, in association with unremarkable development of secondary sexual characteristics and normal 46, XX karyotype. This disorder can be isolated (type I; OMIM 277000) and comprises the so-called CAUV (Congenital Absence of the Uterus and Vagina) and MA (Müllerian Aplasia), or associated with renal, skeletal and/or hearing defects. Cardiac and digital anomalies are rare. Patients with associated anomalies are classified as MURCS association (MÜllerian duct aplasia, Renal Dysplasia and Cervical Somite anomalies), also indicated as MRKH type II syndrome (OMIM 601076), or GRES (Genital Renal Ear Syndrome)(OMIM 267400) if the middle ear is also affected [1]. The most common coexisting defects affect the upper urinary tract, including unilateral renal agenesis, ectopia of one or both kidneys, renal hypoplasia, horseshoe kidney and hydronephrosis [2]. As thoroughly reviewed in a recent paper [1], several inheritance models have been suggested to explain MRKH syndrome aetiology, including polygenic/multifactorial causes and non-genetic issues. Among non-genetic causes maternal diabetes and the teratogen action of thalidomide-like substances have been proposed. All the hypotheses are likely reliable, suggesting that MRKH has a wide aetiological heterogeneity [1]. The increasing number of familial cases, the pattern of congenital malformations, the cooccurrence of Müllerian aplasia in either recessive and dominant syndromes and the association with chromosome rearrangements (see [3] for a review) indicate that $\mathrm{MRKH}$ is a disorder occurring during embryogenesis, the genetic factors playing a crucial role. So far, WNT4 gene mutations have shown to be responsible for a clinically distinct subtype of this disorder, presenting with Müllerian aplasia and hyperandrogenism, with or without renal aplasia [4].

We report two patients affected by MRKH syndrome resulting from deletion of the same $1.5 \mathrm{Mb}$ segment at $17 \mathrm{q} 12$ band, including TCF2 and LHX1 genes.

\section{Patients}

The two patients with Müllerian aplasia reported in this study were enrolled during a multicentric study of MRKH syndrome. Twenty additional females with a clinical diagnosis of MRHK syndrome without $17 \mathrm{q} 12$ chromosome deletion were investigated for TCF2 and LHX1 gene mutations. All participants were informed about the study and signed a consent form approved by the Ethical Committee of each Institute involved.

\section{Patient I}

This patient was the second child of healthy, non consanguineous parents. The mother was 28 and the father 33 year-old at conception. Family history was unremarkable. Pregnancy was normal and delivery at term by caesarian section, because of maternal indication. Birth weight was $3,250 \mathrm{~g}$ (50 th centile), length $48 \mathrm{~cm}$ ( $10^{\text {th }}$ centile), and Apgar scores were 9 and 10 at 1 and 5 minutes. Growth and psychomotor development were normal, but the girl experienced several episodes of acute cystitis during infancy.

She was referred for a genetic opinion at age of 20 years with a diagnosis of primary amenorrhoea and abnormal genitalia. Weight was $52 \mathrm{~kg}$ (25-50 th centile), height 163 $\mathrm{cm}\left(50^{\text {th }}\right.$ centile), and OFC $54 \mathrm{~cm}\left(25-50^{\text {th }}\right.$ centile). She had mild dysmorphic features, including laterally sparse eyebrows, down slanted palpebral fissures, hypertricosis of upper lip (Figure 1A). A transrectal sonogram showed congenital absence of the uterus, polycystic left ovary $29 \times$ $12 \times 31 \mathrm{~mm}$, and a likely left müllerian remnant $16 \times 18$ $\mathrm{mm}$. The right ovary measured $40 \times 39 \times 45 \mathrm{~mm}$ with a functional cyst of $36 \times 38 \times 44 \mathrm{~mm}$. A pelvic magnetic resonance imaging disclosed normal kidneys, an unusually thin bladder wall, congenital absence of uterus and vagina, bilaterally normal ovaries. Audiogram, ECG, cardiac sonogram and blood glucose level were unremarkable. Standard karyotype was normal (46, XX). At age of 20 years the proband underwent a surgical corrective procedure, with the construction of a neo-vagina. Laparoscopic exploration confirmed uterine agenesis, normal ovaries and persisting Müllerian structures. No additional anomaly or congenital defects were associated with the genital malformation.

\section{Patient 2}

This patient was the first child of healthy non consanguineous parents. At birth, the father and mother were 30 and 29 year-old respectively. A younger sister was normal. Family history was negative for renal, genital or skeletal defects. Pregnancy was unremarkable until the $7^{\text {th }}$ month, when US scan disclosed bilateral foetal renal cysts. Chromosome analysis on amniocytes was normal (46, XX). The baby was born at term by caesarean section for obstetric reasons. Birth weight was $3,530 \mathrm{~g}\left(50^{\text {th }}\right.$ centile) and length $51 \mathrm{~cm}\left(75^{\text {th }}\right.$ centile $)$.

The patient came to our observation for the first time at the age of 10 months for evaluation of renal cysts and then revaluated periodically in the subsequent years. Renal ultrasound at age of 5 years showed bilaterally small-sized multicystic kidneys. Both kidneys had diffuse parenchymal hyperecogenicity, poor cortico-medullary differentiation, and small subcapsular cysts. The collecting system was not dilated and urinary bladder wall was 

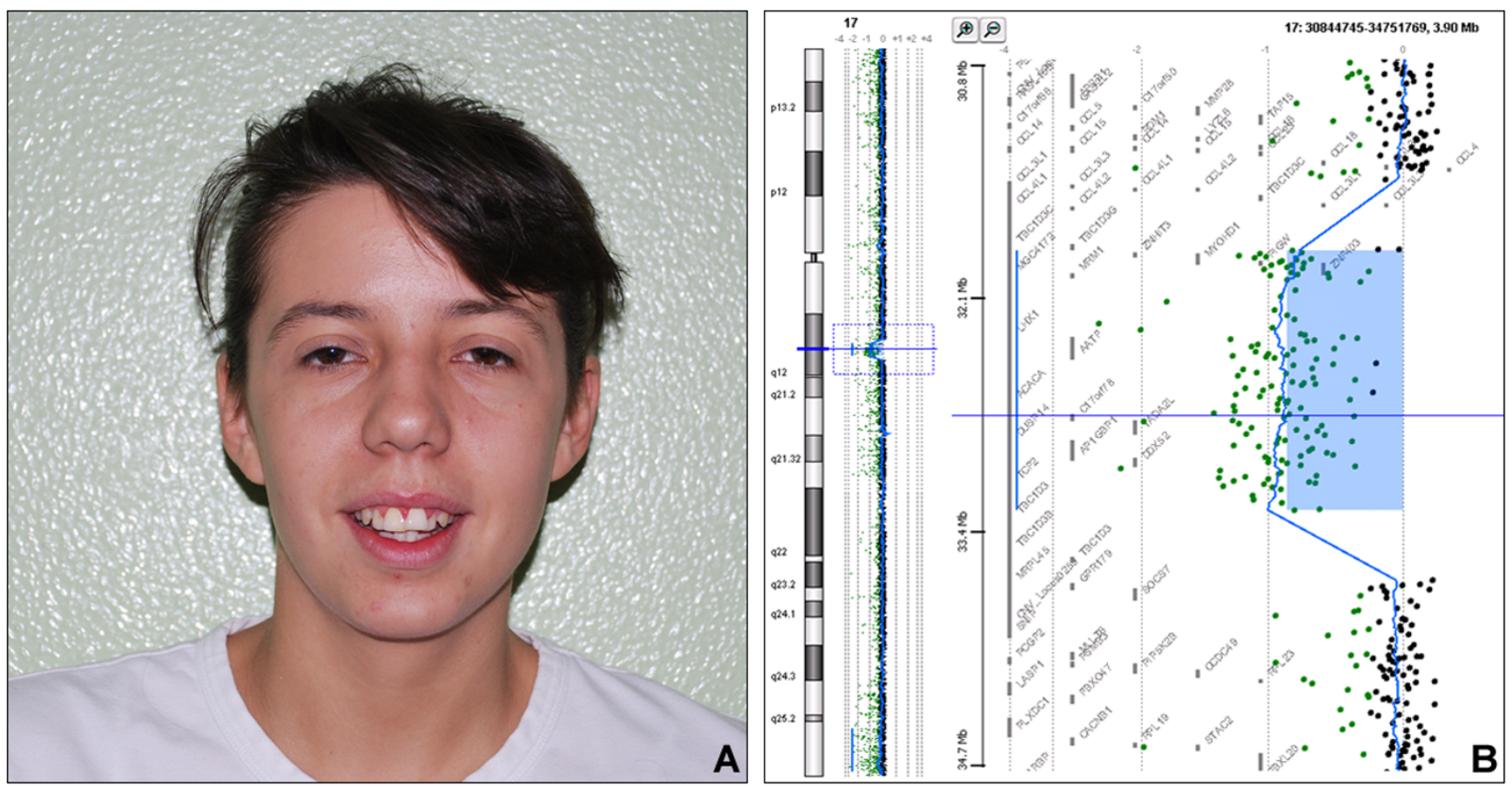

Figure I

A) Patient I: facial appearance showing mild dysmorphisms. B) Detail of array-CGH graphical overview of I7q 12 deletion spanning about I.5 Mb from A_I6_P20635582 (3I,897,238 Mb) to A_I6_P20639I70 (33,322,972 Mb) probes.

regular. These changes were confirmed in subsequent ultrasounds. The developmental milestones and psychomotor development were normal. At the age of 12 years, menarche was complicated by haematocolpos due to agenesis of the upper and middle thirds of vagina, which were surgically corrected. Laparoscopy demonstrated Müllerian malformations with right unicornuate uterus, no cavitating rudimentary left horn, right hematosalpinx and surgically corrected agenesis of the upper and middle thirds of vagina. Ophtalmologic examination, ECG, 24 hour holter measurement, renal function test, liver function test, parathyroid hormone measurement, blood glucose level, uric acid level, blood protein level, 24 hour proteinuria and oxaluria were unremarkable.

At age of 15 years weight was $62.5 \mathrm{Kg}$ (75-90 th centile), height $168 \mathrm{~cm}\left(75-90^{\text {th }}\right.$ centile), and OFC $55.8 \mathrm{~cm}(50-$ $98^{\text {th }}$ centile).

\section{Methods}

\section{Array-CGH}

Genomic oligonucleotide-array (244 K; Agilent Technologies Inc., Palo Alto, CA) was used according to standard protocol with some modifications. For each patient genomic DNA was extracted from $2 \mathrm{ml}$ of an EDTA blood sample. Patients' DNA and a female reference DNA
(Promega, Madison, WI) were Alu I and Rsa I doubledigested (Promega) and purified using DNA Clean and Concentrator Kit (Zymo Research Corporation; Orange; CA). Digested DNA was quantified by the fluorimeter (BioRad, Hercules, CA) and $1 \mu \mathrm{g}$ of each patient and reference DNA were labelled with Cy5-dCTP and Cy3-dCTP (Agilent Technologies Inc.). The Cy5 and Cy3 labelled DNAs were combined and cleaned-up using Micron YM30 columns (Millipore, Bedford, MA). After the addition of blocking agents and the hybridisation buffer (Agilent Technologies, Palo Alto, CA), DNAs were denaturated at $95^{\circ} \mathrm{C}$ and hybridised at $65^{\circ} \mathrm{C}$ for 40 hours with rotation. After washes, dried slides were immediately scanned on the Agilent scanner, imaged with Feature Extraction software (v8.5.3) and analysed using the DNA analytics software (v4.0) (Agilent Technologies Inc.).

A chromosome 17 custom-microarray was designed in silico using the web Agilent eArray database version 4.5 https://earray.chem.agilent.com/earray, in order to test other MRKH patients for the $17 \mathrm{q} 12$ deletion and to eventually compare the size of the rearrangements. All the Agilent's high-density CGH probes mapping to chromosome 17 were included in the array format $8 \times 15 \mathrm{~K}$. The Agilentoptimized chromosome $\mathrm{X}$ probes have been used as control (March 2006 release). 


\section{FISH}

Deletions were confirmed by FISH analysis using RP1119G24 clone selected from the $32 \mathrm{~K}$ genomic library (BACPAC Resources Center; http://bacpac.chori.org/), based on mapping data (UCSC; http://genome.ucsc.edu., March 2006 release). DNA was extracted by a Quantum Prep MiniPrep Kit (BioRad, Hercules, CA) and SpectrumGreen-dUTP or SpectrumOrange-dUTP labeled using the Nick Translation kit (Vysis Inc., Downers Grove, IL) according to the manufacturer's protocol. Metaphase spreads were obtained following standard procedures and FISH analysis was performed as previously described [5].

\section{Mutational Analysis}

To amplify the entire coding sequence and flanking intronic portions of TCF 2 and $L H X 1,9$ and 5 primer pairs were designed respectively. The PCR reactions (except LHX1 exon 2) were performed in a $25 \mu \mathrm{l}$ volume containing $1.5 \mathrm{mM} \mathrm{MgCl}_{2}, 250 \mu \mathrm{M}$ dNTPs, $1 \mu \mathrm{M}$ of each primer, $50 \mathrm{ng}$ of genomic DNA and $1.5 \mathrm{U}$ of AmpliTaq Gold DNA polymerase (Applied Biosystem, Foster City, CA) with an initial denaturation step of $12 \mathrm{~min}$ at $95^{\circ} \mathrm{C}$ followed by 35 cycles at $94^{\circ} \mathrm{C}, 30 \mathrm{sec} ; 60^{\circ} \mathrm{C}, 30 \mathrm{sec} ; 72^{\circ} \mathrm{C}, 30 \mathrm{sec}$ and a final elongation of $7 \mathrm{~min}$ at $72^{\circ} \mathrm{C}$. LHX1 exon 2 (high GC content) has been amplified in a $25 \mu \mathrm{l}$ volume containing $1 \mathrm{mM} \mathrm{MgSO}$, 0.6× PCR Enhancer Solution, 250 $\mu \mathrm{M}$ dNTPs, $1 \mu \mathrm{M}$ of each primer, $50 \mathrm{ng}$ of genomic DNA and $1.5 \mathrm{U}$ of Platinum Pfx DNA Polymerase (Invitrogen, Carlsbad, CA). PCR products were purified using ExoSAPIT (USB Corporation, Cleveland, $\mathrm{OH}$ ) and sequenced directly on an automated sequencer (ABI 3100; Applied Biosystem) using the ABI-PRISM big-dye Terminator Cycle Sequencing Ready Reaction kit (Applied Biosystem).

\section{Results}

Array-CGH analysis performed on patients 1 and 2 disclosed a de novo deletion at 17q12 band (Figure 1B) confirmed by FISH using a specific BAC clone. FISH analysis extended to parents showed a normal hybridization pattern, demonstrating the de novo origin of the rearrangement. In both cases the deletion spanned about $1.5 \mathrm{Mb}$ from A_16_P20635582 to A_16_P20639170 (31.897.238-33.322.972 Mb) probes (UCSC Genome Browser; http://genome.ucsc.edu, March 2006 Release), including 16 RefSeq genes, and it was not listed among the copy number polymorphisms (Database of Genomic Variants; http://projects.tcag.ca/variation/). Subsequently, 20 consecutive patients with a clinical diagnosis of $\mathrm{MRKH}$ syndrome were tested by a focused chromosome 17 arrayCGH analysis in order to assess the prevalence of $17 \mathrm{q} 12$ deletion in females affected by MRKH. This analysis was negative. These 20 patients were investigated also by direct sequencing of candidate genes mapping to $17 \mathrm{q} 12$ (TCF2 and LHX1). Molecular testing disclosed a number of known polymorphisms, but no pathogenic mutation (Table 1).

\section{Discussion}

An increasing number of familial cases suggest that MRKH syndrome can be inherited as an autosomal dominant incompletely penetrant trait, either due to single gene mutation or chromosomal imbalances [1]. Clinical features are consistent with a developmental defect attributable to an initial affection of the intermediate mesoderm leading to an alteration of the blastema of the cervicotho-

Table I: Mutational analysis of candidate-genes

\begin{tabular}{|c|c|c|}
\hline Patient ID & TCF2 & LHXI \\
\hline \multicolumn{3}{|l|}{ RKIO4 } \\
\hline RK 105 & $|654-2| \mathrm{C} / \mathrm{T}$ & \\
\hline RKI06 & & $84 I+26 \mathrm{~A} / \mathrm{G}$ \\
\hline RK 107 & & $84 I+26 \mathrm{~A} / \mathrm{G}$ \\
\hline RKIII & $|654-2| \mathrm{C} / \mathrm{T}$ & NO DNA \\
\hline RKII2 & I653+48insC; $1654-21 \mathrm{C} / \mathrm{T}$ & \\
\hline RKII3 & $|654-2| \mathrm{T} / \mathrm{T}$ & \\
\hline RKII4 & $|654-2| \mathrm{C} / \mathrm{T}$ & \\
\hline RKII5 & & $170+42 \mathrm{G} / \mathrm{T}$ \\
\hline RKII6 & I654-2| C/T & \\
\hline \multicolumn{3}{|l|}{ RKII7 } \\
\hline RKII8 & & $676-34 \mathrm{C} / \mathrm{T} ; 84 \mathrm{I}+26 \mathrm{~A} / \mathrm{G}$ \\
\hline RKII9 & & $84 I+26 \mathrm{~A} / \mathrm{G}$ \\
\hline RK 120 & $|654-2| \mathrm{C} / \mathrm{T}$ & \\
\hline RKI2I & $1653+48$ ins $C$ & \\
\hline RK 122 & $|654-2| \mathrm{T} / \mathrm{T}$ & \\
\hline RK 123 & $|654-2| \mathrm{C} / \mathrm{T}$ & \\
\hline \multicolumn{3}{|l|}{ RKI24 } \\
\hline RKI25 & $1653+48$ ins $C$ & \\
\hline
\end{tabular}

RKI26

List of the known polymorphisms disclosed by the mutational analysis of $L H X I$ and TCF2 genes in 20 selected chromosomally normal MRKH females, tested negative for $17 q 12$ deletion. 
racic somites and the pronephric ducts [6], but developmental genes investigated, such as WT1, HOXA7, HOXA13 and PBX1, did not reveal any pathogenic mutation $[7,8]$. Among chromosome causes, an identical $\mathrm{t}(12 ; 14)(\mathrm{q} 14 ; \mathrm{q} 31)$ detected in two unrelated Indian females, a maternally inherited terminal deletion of $4 \mathrm{q}$ and 22q11.21 deletion, overlapping the DiGeorge syndrome region, have been described in females with syndromic MRKH. However, so far no candidate gene was identified in the unbalanced regions [9-11].

Array-CGH technique has offered in the last years new opportunities to discover cryptic chromosome imbalances causative of congenital malformations. This approach allowed Cheroki et al. to confirm the involvement of 22q region in the MRKH aetiology [12] and to detect a de novo deletion at $17 \mathrm{q} 12$ in one patient presenting with absent uterus, severe learning disability and seizures, without diabetes and renal malformations [13]. We have reported two patients evaluated for Müllerian ducts aplasia in which array-CGH analysis disclosed an identical deletion at chromosome $17 \mathrm{q} 12$, spanning about 1.5 $\mathrm{Mb}$ of genomic DNA. One patient displayed congenital absence of uterus and vagina, with bilaterally normal ovaries without any additional anomaly, while the other had agenesis of the upper part of vagina, right unicornuate uterus and non cavitating rudimentary left horn associated with bilaterally multicystic kidneys. In both patients psychomotor development was normal. This is a rare albeit recurrent imbalance detected so far in a few other subjects investigated using genomic microarray. Mefford et al. identified the same $1.5 \mathrm{Mb}$ deletion in a foetus presenting with grossly abnormal, dysplastic multicystic kidneys and compared this case with five paediatric patients with renal disease and three subjects affected by isolated MODY5. It was found that the breakpoints were identical in all but one case, who displayed a larger deletion, and occurred at segmental-duplication clusters with multiple regions of high identity (up to 99\%) [14]. The deleted segment encompassed 16 known genes, including TCF 2 and LHX1. Mutations in TCF2 gene, also known as hepatocyte nuclear factor-1-beta $(H N F 1 \beta)$, which occur in individuals affected by maturity-onset diabetes of the young type 5 (MODY5; MIM 137920) and renal manifestations [15], have been associated with Müllerian disorders [1]. In particular, two of four affected females in a MODY5 family segregating TCF2 mutations had Müllerian aplasia [16], while in another MODY5 family, the proband displayed cystic kidneys and uterus didelphys and her affected second son had renal cysts and hypospadias [17]. TCF2 is expressed in renal metanephroi at preglomerular stages during metanephrogenesis [18]. Urinary and genital system are embryologically correlated, both originating from a common mesodermal ridge. Edghill et al. [19] have estimated that about $10 \%$ of subjects with TCF2 mutations also display some genital system anomaly. LHX1 encodes a transcription factor with a DNA-binding homeodomain and two cysteine-rich LIM domains that are thought to be involved in protein-protein interactions [20]. In mouse, this gene was shown to be involved in genitourinary system developmental processes, including Müllerian ducts [21]. To assess the contribution of these genes to MRKH syndrome, we performed a mutational analysis of 20 non deleted MRKH females. Analysis of 40 chromosomes disclosed several polymorphic changes, in the absence of any pathogenic variation.

\section{Conclusion}

The recurrent $17 \mathrm{q} 12$ deletion is associated with a wide clinical spectrum which is further expanded by the patients reported in this study. Indeed, 17q12 deletion appears to be pathogenetically related with a subset of individuals affected by MRKH syndrome, with or without renal disease. The present data also recommend searching for $17 \mathrm{q} 12$ hemizygosity and/or mutations in the candidate TCF2 and LHX1 genes, both in type I and type II MRKH syndrome.

\section{Competing interests}

The authors declare that they have no competing interests.

\section{Authors' contributions}

This paper reports the results of a multicenter study: clinical evaluation of patients, including dysmorphologic, cardiac, urogenital and gynecologic examination, has been performed by AB, GF, GB, MTD, LF and MM; LB drafted the manuscript and participated in microarray analysis; SG, CG, MC, AN and FB performed cytogenetic and molecular studies; FL and BD critically revised the manuscript and have given final approval of the version to be published. All authors read and approved the final manuscript.

\section{Consent}

Written informed consent was obtained from the patient for publication of the accompanying image.

\section{Acknowledgements}

We are grateful to the patients and their family members. This work was supported in part by a grant from the Italian Ministry of Health (Ricerca Corrente 2009).

\section{References}

I. Morcel K, Camborieux L, Guerrier D: Mayer-Rokitansky-KusterHauser (MRKH) syndrome. Orphanet J Rare Dis 2007, 2:I3.

2. Pittock ST, Babovic-Vuksanovic D, Lteif A: Mayer-RokitanskyKuster-Hauser anomaly and its associated malformations. Am J Med Genet A 2005, 135:3 |4-316.

3. Simpson JL: Genetics of the female reproductive ducts. $A m \mathrm{~J}$ Med Genet 1999, 89:224-239.

4. Biason-Lauber A, De Filippo G, Konrad D, Scarano G, Nazzaro A Schoenle EJ: WNT4 deficiency--a clinical phenotype distinct from the classic Mayer-Rokitansky-Kuster-Hauser syndrome: a case report. Hum Reprod 2007, 22:224-229. 
5. Bernardini L, Castori M, Capalbo A, Mokini V, Mingarelli R, Simi P, Bertuccelli A, Novelli A, Dallapiccola B: Syndromic craniosynostosis due to complex chromosome 5 rearrangement and MSX2 gene triplication. Am J Med Genet A 2007, I 43A:2937-2943.

6. Duncan PA, Shapiro LR, Stangel JJ, Klein RM, Addonizio JC: The MURCS association: Mullerian duct aplasia, renal aplasia, and cervicothoracic somite dysplasia. I Pediatr 1979, 95:399-402.

7. van Lingen BL, Reindollar RH, Davis AJ, Gray MR: Further evidence that the WTI gene does not have a role in the development of the derivatives of the mullerian duct. Am J Obstet Gynecol 1998, 179:597-603.

8. Burel A, Mouchel T, Odent S, Tiker F, Knebelmann B, Pellerin I, Guerrier D: Role of HOXA7 to HOXAI 3 and PBXI genes in various forms of MRKH syndrome (congenital absence of uterus and vagina). J Negat Results Biomed 2006, 5:4.

9. Kucheria K, Taneja N, Kinra G: Autosomal translocation of chromosomes I 2q \& I 4q in mullerian duct failure. Indian J Med Res 1988, 87:290-292.

10. Devriendt K, Moerman P, Van Schoubroeck D, Vandenberghe K, Fryns JP: Chromosome 22q I I deletion presenting as the Potter sequence. J Med Genet 1997, 34:423-425.

II. Bendavid C, Pasquier L, Watrin T, Morcel K, Lucas J, Gicquel I, Dubourg C, Henry C, David V, Odent S, Leveque J, Pellerin I, Guerrier D: Phenotypic variability of a 4q34-->qter inherited deletion: MRKH syndrome in the daughter, cardiac defect and Fallopian tube cancer in the mother. Eur J Med Genet 2007, 50:66-72.

12. Cheroki C, Krepischi-Santos AC, Rosenberg C, Jehee FS, MingroniNetto RC, Pavanello Filho I, Zanforlin Filho S, Kim CA, Bagnoli VR, Mendonca BB, Szuhai K, Otto PA: Report of a del22qII in a patient with Mayer-Rokitansky-Kuster-Hauser (MRKH) anomaly and exclusion of WNT-4, RAR-gamma, and RXRalpha as major genes determining MRKH anomaly in a study of 25 affected women. Am J Med Genet A 2006, I 40:1339-1342.

13. Cheroki C, Krepischi-Santos AC, Szuhai K, Brenner V, Kim CA, Otto PA, Rosenberg C: Genomic imbalances associated with mullerian aplasia. J Med Genet 2008, 45:228-232.

14. Mefford HC, Clauin S, Sharp AJ, Moller RS, Ullmann R, Kapur R, Pinkel D, Cooper GM, Ventura M, Ropers HH, Tommerup N, Eichler EE, Bellanne-Chantelot C: Recurrent reciprocal genomic rearrangements of $17 \mathrm{qI} 2$ are associated with renal disease, diabetes, and epilepsy. Am J Hum Genet 2007, 81:1057-1069.

15. Horikawa $Y$, Iwasaki N, Hara M, Furuta $\mathrm{H}$, Hinokio $Y$, Cockburn BN, Lindner T, Yamagata K, Ogata M, Tomonaga O, Kuroki H, Kasahara $\mathrm{T}$, Iwamoto $\mathrm{Y}$, Bell GI: Mutation in hepatocyte nuclear factor-I beta gene (TCF2) associated with MODY. Nat Genet 1997, 17:384-385.

16. Lindner TH, Njolstad PR, Horikawa Y, Bostad L, Bell GI, Sovik O: A novel syndrome of diabetes mellitus, renal dysfunction and genital malformation associated with a partial deletion of the pseudo-POU domain of hepatocyte nuclear factorIbeta. Hum Mol Genet 1999, 8:200I-2008.

17. Bingham C, Ellard S, Cole TR, Jones KE, Allen LI, Goodship JA, Goodship TH, Bakalinova-Pugh D, Russell GI, Woolf AS, Nicholls AJ, Hattersley AT: Solitary functioning kidney and diverse genital tract malformations associated with hepatocyte nuclear factor-I beta mutations. Kidney Int 2002, 6 I: |243- I 25I.

18. Kolatsi-Joannou M, Bingham C, Ellard S, Bulman MP, Allen LI, Hattersley AT, Woolf AS: Hepatocyte nuclear factor-I beta: a new kindred with renal cysts and diabetes and gene expression in normal human development. J Am Soc Nephrol 200I, I 2:2175-2|80.

19. Edghill EL, Bingham C, Ellard S, Hattersley AT: Mutations in hepatocyte nuclear factor-Ibeta and their related phenotypes. J Med Genet 2006, 43:84-90.

20. Hunter CS, Rhodes SJ: LIM-homeodomain genes in mammalian development and human disease. Mol Biol Rep 2005, 32:67-77.

21. Kobayashi A, Kwan KM, Carroll TJ, McMahon AP, Mendelsohn CL, Behringer RR: Distinct and sequential tissue-specific activities of the LIM-class homeobox gene Lim I for tubular morphogenesis during kidney development. Development 2005, 132:2809-2823.
Publish with BioMed Central and every scientist can read your work free of charge

"BioMed Central will be the most significant development for disseminating the results of biomedical research in our lifetime. "

Sir Paul Nurse, Cancer Research UK

Your research papers will be:

- available free of charge to the entire biomedical community

- peer reviewed and published immediately upon acceptance

- cited in PubMed and archived on PubMed Central

- yours - you keep the copyright

Submit your manuscript here:

http://www.biomedcentral.com/info/publishing_adv.asp
BioMedcentral 